\title{
Treatment of Depression in General Practice
}

\author{
D. A. W. JOHNSON
}

British Medical fournal, 1973, 2, 18-20

\section{Summary}

With the co-operation of the family doctors in five selected urban general practices the general-practitioner treatment of 73 patients suffering from a new episode of depressive illness was evaluated over a period of four months. The purpose was to test the belief that general practitioners are best fitted to manage most psychological ailments, and depression was chosen as the psychiatric illness most commonly seen in general practice. Medication was the principal treatment offered, and this was often inadequate in dosage or the patient defaulted. Drug defaulting was thought to be due partly to failure of supervision and follow-up and to too low a consultation rate. The low consultation rate was also thought to explain why few patients thought there was a therapeutic value in the doctorpatient relationship. The results of the study indicate that patients with depressive illness do not receive the best treatment in general practice. The reasons are several and responsibility must be shared by the medical practitioners, the current system of the general practice, and the patients themselves.

\section{Introduction}

Because of their knowledge of their patients and their family background general practitioners have been held to be best fitted to manage most psychological ailments (College of General Practitioners, 1958). This paper reports a study of how effectively depression, the psychiatric illness most often diagnosed by general practitioners, was treated in general practice. In particular the study attempted to evaluate the doctor-patient relationship, the therapeutic importance of which is emphasized by the advocates of general-practitioner psychiatry.

\section{Practices}

Shepherd et al. (1964) tried and failed to obtain a random sample of doctors for their survey of minor mental illness in general practice in London, and they concluded that such a sample was impracticable. I therefore chose for this study five practices which were held in high esteem by medical colleagues and by me and which seemed to represent a crosssection of general practitioners and of general practices. The number of doctors in the five practices totalled 14.

\section{Patients and Methods}

The general practitioners were asked to notify me of the first attendance of all patients with a new episode of depressive illness - that is, those who had been free from symptoms and had had no treatment for a year-to record the presenting symptoms and mode of presentation, and to continue to keep a record of all consultations and treatment given over a fourmonth period of surveillance.

\section{University of Manchester}

D. A. W. JOHNSON, M.SC., M.R.C.PSYCH., Lecturer in Psychiatry (Present appointment: Consultant Psychiatrist, Crumpsall Hospital, Manchester 8)
Each patient together with a relative was interviewed at home by me. At the first interview, within seven days of the initial general-practitioner consultation, a modified Maudsleytype history, as used in the University of Manchester, was taken, and a Kendell diagnostic index and the Beck depressive inventory completed. Only patients in whom the diagnosis of primary depressive illness was confirmed by me and in whom 11 or more was scored on the Beck inventory were accepted for the survey. Those accepted were again interviewed, with a relative, four to six weeks later and for a third and final time 10-12 weeks after that-that was 16-18 weeks after the initial general-practitioner consultation. The Beck inventory was repeated at each interview and a symptomchange rating made on a five-point scale. Changes in stress and environment were noted.

Observations on treatment were made under three headings: (1) drug treatment; (2) psychotherapy, including the functioning of the doctor-patient relationship and generalpractitioner supportive role; and (3) social intervention and use of social agencies.

The amount of defaulting on drug treatment was estimated by questioning patients and relatives and by tablet counts and comoaring the results with the general practitioners' records. The patients' reasons for drug defaulting were discussed with them.

In evaluating the therapeutic potential of the doctor-patient relationship patients were asked how long they had been registered with their doctor, and patients and relatives were asked to rate on a four-point scale how well the family doctor knew the patient. This took into consideration the doctor's contact with the family as a whole. Patients also rated on a four-point scale their satisfaction with their doctor in general and not specifically in relation to the current illness, and, finally, they rated their doctor in terms of the personal help and support offered during the current illness. The patients made the ratings after their recovery from depression. The frequency of patient-doctor contact during the illness was among the factors taken into account in evaluating the doctor's psychotherapeutic support.

Stress identified by the patient, and confirmed by a relative or by the patient on recovery, was recorded as a measure of the need for social intervention, though not all forms of stress are susceptible to this treatment.

\section{Results}

The number of patients referred by the general practitioners was 112. Of these, eight refused interview, six were admitted to hospital, and seven were not interviewed for various administrative reasons. The remaining 91 patients were interviewed by me. Eighteen of these were excluded at the first interview: two were not depressed, one had been treated within the previous year, and in 15 the primary diagnosis was thought to be a personality disorder. The results were therefore of a study of 73 patients.

Their ages ranged from 17 to 80 years and $56 \%$ were within the $30-50$ age group. The female to male ratio was $2: 1$. In half of the cases the illness prevented the patients from carrying out their normal work, and in one-fifth of the cases the Beck depressive inventory score was over 20. Presenting symptoms were obviously psychological with no organic disease in $60 \%$ of the patients, and indicative of depressive 
illness associated with definite organic disorder in $20 \%$. In $18 \%$ somatic complaints masked underlying depression without overt psychological symptoms. Associated organic disease was commoner in the elderly. A change of mood was most often the principal presenting symptom. Sixty per cent. of the patients complained of depression, $22 \%$ of tiredness or loss of energy, $17 \%$ of pain, and $11 \%$ of general irritability. Forty per cent. of patients presented within four weeks of the onset of symptoms.

\section{DRUG TREATMENT}

Only $72 \%$ of the 73 patients, including those who were instructed to increase their medication over a period, were prescribed antidepressant drugs in a dose usually regarded as therapeutic (table I). Their potential therapeutic benefit was greatly reduced by the patients' own actions, for $16 \%$ stopped taking their drugs within a week, $41 \%$ within a fortnight, $59 \%$ within 21 days, and $68 \%$ within a month. None who stopped before the end of the third week could have taken a therapeutic course of treatment, and few who stopped before the end of the fourth week could have gained full therapeutic benefit. In nearly every case medication was stopped without the doctor knowing.

TABLE I-Treatment Prescribed by General Practitioner at Initial Consultation (73 Patients)

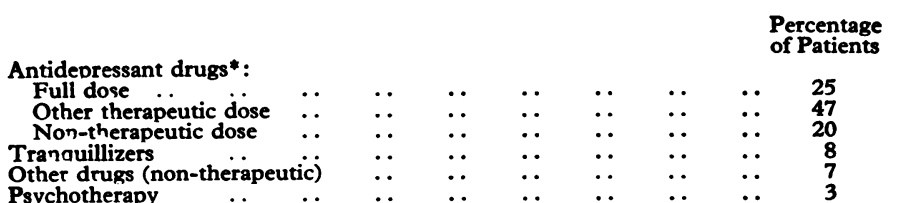

$\begin{array}{llllllllll}\text { Psychotherapy } & . & \ldots & . & \ldots & \ldots & \ldots & \ldots & \ldots & 3\end{array}$ Full dose $=$ more than $75 \mathrm{mg}$ amitriptyline daily or equivalent. Other therapeutic than $30 \mathrm{mg}$ amitriptyline daily or equivalent.

The therapeutic potential of drug treatment among the 47 patients still suffering from depression when seen at the second interview was further reduced (table II). The $39 \%$ not receiving treatment were no longer attending their doctor. Drug defaulting was still found to be a major problem at the third and final interview. Though still suffering from depression $17(59 \%)$ out of 29 patients prescribed medication after the second interview had stopped taking it without their doctor knowing. Four patients had had their medication stopped by their doctor. Only four of the eight still taking medication were doing so regularly.

TABLE II-Treatment of Patients Still Suffering from Depression when seen at Second Interview at 4-6 weeks (47 Patients)

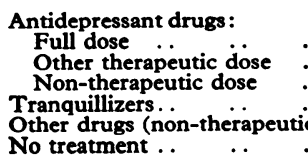

$\begin{array}{ll} & \\ \cdots & \cdots \\ \cdots & \cdots \\ \cdots & \cdots \\ \cdots & \cdots\end{array}$

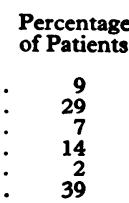

There was no single explanation for drug defaulting. Nineteen patients $(26 \%)$ stopped their medication when they felt improved. Most of them had thought continued medication unnecessary. Fifteen $(21 \%)$ stopped when the original prescription for drugs had been taken, stating that they had received no other instructions from their doctor, though many admitted they had been influenced by their own attitudes to drugs as a form of treatment. A further 15 patients stated they disbelieved in pills. This reflected their attitude to psychiatry or their beliefs about the cause of emotional illness as much as their attitude to drugs. Five patients stopped their medication because of side effects, though one-third of all patients reported some side effects. An attempt to relate personality to drug defaulting with the Maudsley Personality Inventory failed to show any significant correlation between either the $\mathrm{E}$ or $\mathrm{N}$ score and drug defaulting.

\section{PSYCHOTHERAPY}

Only two patients were specifically offered psychotherapy. Neither patient returned to see the doctor.

Half of the 73 patients had been registered with their family doctor for five years or less, a quarter for from six to 10 years, and a quarter for 10 years or more. Only $17 \%$ of the patients thought they were well known to their family doctor, $30 \%$ thought they were known, $23 \%$ thought they were hardly known, and $30 \%$ were certain that they were completely unknown.

Half of the patients rated their general practitioner as satisfactory, $33 \%$ as good, and $8 \%$ as very good. Only $8 \%$ expressed dissarisfaction. Despite the general high regard for the doctor, only $15 \%$ of patients acknowledged any personal help or support in their current illness and $12 \%$ thought their doctor's attitude had been unhelpful.

During the period between their first and second interview with me $39(53 \%)$ of the 73 patients had consulted their doctor once, $28(38 \%)$ twice, $6(8 \%)$ three times, and one more than three times (table III). Of the 47 patients still suffering from depression at the second interview 20 did not consult their doctor between then and the final interview, 13 consulted him once, 7 twice, 6 thrice, and 1 four or more times.

TABLE III-Numbers of Consultations with General Practitioner in Periods 0-6 Weeks (73 patients) and 7 to 18 weeks (47 Patients)

\begin{tabular}{|c|c|c|c|c|c|}
\hline \multicolumn{4}{|c|}{ No. of Consultations } & \multicolumn{2}{|c|}{ No. of Patients } \\
\hline $\begin{array}{ll}\text { None } & . \\
\text { One } & . \\
\text { Two } & . \\
\text { Three } & \text { Four or more } \\
\text { Four }\end{array}$ & $\begin{array}{l}\cdots \\
\cdots \\
\cdots\end{array}$ & $\begin{array}{l}\ldots \\
\because \\
\cdots\end{array}$ & $\begin{array}{l}\because \\
\because \\
\because \\
.\end{array}$ & $\begin{array}{c}\begin{array}{c}0-6 \text { Weeks } \\
(\mathrm{n}=73)\end{array} \\
\begin{array}{c}39(53 \%) \\
28(38 \%) \\
6(8 \%) \\
1(1 \%)\end{array}\end{array}$ & $\begin{array}{c}7-18 \text { Weeks } \\
\text { (n = 47) } \\
20(43 \%) \\
13(28 \%) \\
7(15 \%) \\
6(12 \%) \\
1(2 \%)\end{array}$ \\
\hline
\end{tabular}

\section{SOCIAL TREATMENT}

A stress factor was associated, but not necessarily causatively, with the onset of depression in $59(81 \%)$ of the patients (table IV). No doctor attempted to modify or influence the precipitating factors in any way. No social agencies took part in the treatment of patients. This was particularly important, since the resolution of stress factors had a statistically significant $(P<0.01)$ positive correlation with improvement in the patients' clinical condition.

TABLE IV-Incidence and Nature of Stress Factors in 73 Patients Studied

\begin{tabular}{|c|c|c|c|c|}
\hline \multirow{2}{*}{\multicolumn{2}{|c|}{ Nature of Stress }} & \multicolumn{3}{|c|}{ Proportion of Patients Suffering Stress } \\
\hline & & $\begin{array}{l}\text { At Onset } \\
(\%)\end{array}$ & $\begin{array}{c}\text { At 4-6 Weeks } \\
(\%)\end{array}$ & 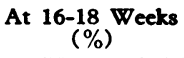 \\
\hline $\begin{array}{l}\text { Psychological } \\
\text { Occupational } \\
\text { Marital } \\
\text { Physical } \\
\text { Sexual } \\
\text { Environment } \\
\text { Multiple } \\
\text { None }\end{array}$ & $\begin{array}{l}\ldots \\
\because \\
\cdots \\
\cdots \\
\cdots\end{array}$ & $\begin{array}{r}11 \\
11 \\
6 \\
22 \\
1 \\
24 \\
6 \\
19\end{array}$ & $\begin{array}{r}6 \\
7 \\
6 \\
1 \\
0 \\
24 \\
5 \\
51\end{array}$ & $\begin{array}{r}6 \\
5 \\
6 \\
1 \\
0 \\
15 \\
5 \\
62\end{array}$ \\
\hline
\end{tabular}




\section{Discussion}

Depressive illness in general practice is not necessarily trivial. Half of the patients in this study were unable to follow their normal life, 22 admitted to suicidal ideas, and two actually took an overdose of drugs. Since most cases of depression are treatable it is important to evaluate critically the treatment prescribed.

Stress was associated with the onset of illness in $81 \%$ of the patients studied, yet only two were offered psychotherapy and none was offered social help. Few thought they had gained any help from the doctor-patient relationship even though they were highly satisfied with their doctors. That the potential for the development of a traditional doctor-patient relationship in a busy urban practice is probably small is supported by the fact that half of the patients had been registered with their family doctors for five years or less and often saw more than one doctor within a partnership. Only half of the patients thought they were known to their family doctors and one-third thought they were quite anonymous within the practice. The relative infrequency of contact between doctor and patient must also have reduced the potential of the supportive role, particularly for the 47 patients whose illness continued after six weeks. Twenty of these had no further consultation with their doctor, and only 14 saw their doctor on two or more occasions during a threemonth period.

The potential of medication, the principal treatment offered, was limited from the start. Only $72 \%$ of the patients were prescribed antidepressant drugs in a dose usually regarded as therapeutic. What was more, the longer patients remained ill the less likely were they to receive a therapeutic dose. The drug-defaulting rate was disturbingly high, and an analysis of the reasons given for discontinuing medication showed a failure of doctor-patient communication. This was not unexpected, since Ley and Spelman (1967) found that under ideal conditions outpatients forgot between one-third and one-half of instructions given them. But it emphasizes the need for frequent doctor-patient contact for explanation and supervision of the drug regimen.

The lowest incidences of drug-defaulting have been associated with intensive follow-up (Porter 1969; Blashki et al., 1971). The high rate of drug-defaulting among the patients in the study reported here was probäbly a reflection of the low consultation rate. A view widely expressed among general practitioners is that patients do not tolerate full therapeutic doses of drugs because of their side effects. There was little evidence in this study to support this view. Only $7 \%$ of patients stopped their medication because of side effects.

The cases of depression seen in these general practices seem, despite an apparent lack of adequate treatment, to have been mostly a self-limiting illness. But that should not give rise to complacency, since the risk of suicide in depressive illness is high and there is no way of predicting which cases will resolve. Also, since most cases of depression respond well to adequate treatment, its potential for reducing suffering and discomfort to patients and their families is great.

\section{Conclusion}

This study indicates that patients with depressive illness do not receive the best possible treatment. It raises doubts whether in the treatment of people with psychological illness in busy urban general practices "every general practitioner starts with an advantage over the consultant because of his knowledge of his patients and the background against which they live their lives, his accessibility to their families, and the continuity of his contact, perhaps over generations" (College of General Practitioners, 1958). The results suggest that family doctors need to be more aware of the stresses of their patients and to be readier to call in the appropriate social agency. They should also be prepared actively to supervise treatment and to use the full resources of the modern health team to offer a supportive relationship. In depressive illness the frequency of consultation should be determined by the doctor.

Most of the results of this study were included in an M.Sc. thesis submitted to the University of Manchester. I wish to thank Professor W. I. N. Kessel for his help and encouragement and the general practitioners who collaborated in the survey.

\section{References}

Blashki, T. G., Mowbray, R., and Davies, B. (1971), British Medical fournal,

1, 133 . Ley, P., and Spelman, M. S. (1967). Communicating with the Patient. London, Staoles Press.

Porter, A. M. W. (1969). British Medical fournal, 1, 218.

Shepherd, M., Cooper, B., Brown, A. C., and Kalton, G. W. (1964). British Medical fournal, 2, 1359. 